RELATO DE CASOS

\title{
Intussuscepção Íleo-Cólica em Adulto
}

\author{
Ileocolic Intussusception In Adult
}

\author{
PAULO JOSÉ HAIEK ARAÚJO'; MARCELO FERNANDES RANGEL ${ }^{2}$; THALES PAULO BATISTA ${ }^{3}$
}

\begin{abstract}
${ }^{1}$ Cirurgião Geral do Hospital Geral Santa Isabel - HGSI; Diretor do Curso Advanced Trauma Life Support - ATLS ${ }^{\circledR}$, Paraíba; ${ }^{2}$ Cirurgião Geral do HGSI; Doutor em Medicina pela Universidade Federal do Rio Grande do Sul - UFRGS;

${ }^{3}$ Cirurgião Geral do Hospital Geral Santa Isabel - HGSI.
\end{abstract}

\begin{abstract}
ARAÚJO PJH; RANGEL MF; BATISTA TP. Intussuscepção Íleo-Cólica em Adulto. Rev bras Coloproct, 2008;28(4): $470-473$.
RESUMO: A intussuscepção representa a invaginação de um segmento intestinal sobre outro que, apesar de relativamente comum entre as crianças, raramente acomete os adultos. Nestes, a invaginação intestinal apresenta uma causa bem definida na maioria dos casos e seu quadro clínico costuma ser bastante variável, contudo, poucos deles são diagnosticados no período préoperatório. Um tratamento padrão ainda não pôde ser estabelecido e sua abordagem terapêutica deve ser individualizada, porém frequentemente resulta em ressecções dos segmentos intestinais envolvidos. Este artigo relata o tratamento cirúrgico de um caso de obstrução intestinal em mulher idosa, causada por intussuscepção íleo-cólica. O agente etiológico correspondia a um tumor polipóide em íleo terminal, para a qual a utilização de imuno-histoquímica foi necessária na realização de seu diagnóstico diferencial com GIST.
\end{abstract}

Descritores: Intussuscepção, invaginação, adulto, obstrução intestinal, GIST.

\section{INTRODUÇÃO}

A intussuscepção representa a invaginação de um segmento intestinal sobre outro que, apesar de relativamente comum entre as crianças, raramente acomete os adultos.

Nestes, a intussuscepção apresenta uma causa bem definida na maioria dos casos e seu quadro clínico costuma ser bastante variável. Os principais exames utilizados para seu diagnóstico são radiografia simples do abdômen, exames contrastados, colonoscopia, ultra-sonografia (USG) e tomografia computadorizada (TC), contudo, poucas vezes acaba sendo identificada no pré-operatório.

Seu tratamento requer abordagem individualizada, mas comumente resulta em ressecções dos segmentos intestinais envolvidos, precedidas ou não por redução manual da invaginação.

Relata-se o tratamento cirúrgico de um caso de obstrução intestinal em mulher idosa causada por intussuscepção íleo-cólica e diagnosticada no pré-ope- ratório. Nela, a cabeça da invaginação formou-se por pólipo fibróide inflamatório em íleo terminal, que necessitou da utilização de imuno-histoquímica para seu diagnóstico diferencial com "tumor estromal gastrintestinal" (GIST).

\section{RELATO DO CASO}

Paciente do sexo feminino, 65 anos, admitida no setor de pronto atendimento, referindo dor abdominal e diarréia sanguinolenta persistentes por 8 dias. Ao exame físico apresentava tumoração dolorosa de contornos indefinidos e móvel, palpável em fossa ilíaca e flanco direitos. Após sua admissão hospitalar, evoluiu com distensão abdominal progressivamente mais intensa e parada da eliminação dos gazes intestinais.

Realizou TC do abdômen, além de outros exames complementares para rotina diagnóstica de abdômen agudo, que mostrou "imagem em alvo" característica em seu quadrante inferior direito, a partir do que se concluiu tratar-se de invaginação íleo-cólica (Figura 1).

Trabalho realizado no Hospital Geral Santa Isabel - HGSI, João Pessoa - PB.

Recebido em 05/12/2006

Aceito para publicação em 22/01/2007 
Com o diagnóstico de obstrução intestinal por intussuscepção, submeteu-se à laparotomia exploradora, que confirmou a presença da invaginação íleo-cólica sem sinais de sofrimento vascular dos segmentos envolvidos (Figura 2). Após redução manual desta, realizouse enterectomia segmentar e reconstrução imediata do trânsito intestinal por meio de anastomose término-terminal distante cerca de $5 \mathrm{~cm}$ da junção ileocecal, associada à apendicectomia tática, durante o mesmo procedimento cirúrgico. Aberta a peça no trans-operatório, notou-se a presença de tumor polipóide e friável de aproximadamente $4 \mathrm{~cm}$ em seu maior diâmetro, formando a "cabeça da invaginação" (Figura 3).

A paciente evoluiu sem intercorrências e com progressiva melhora, recebendo alta ao sétimo dia de pós-operatório com orientações sobre seu acompanhamento.

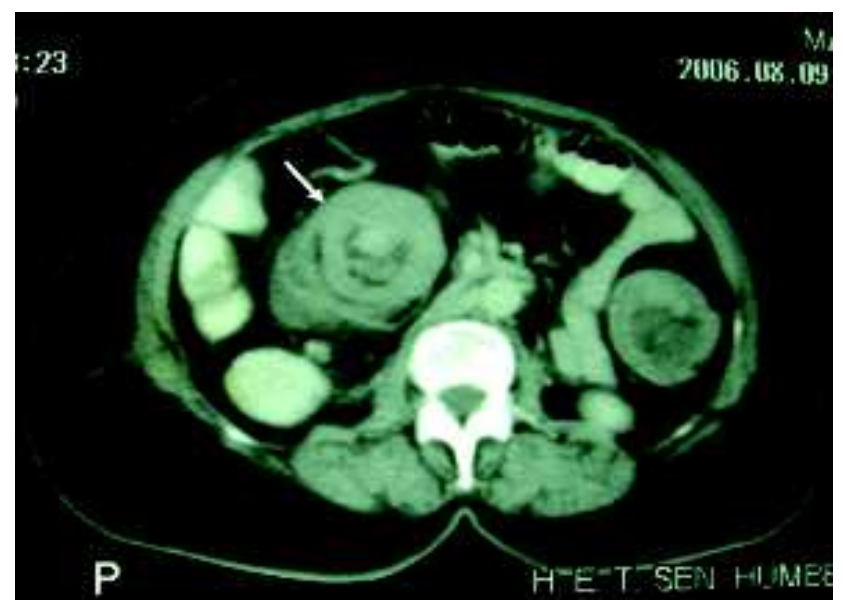

Figura 1 - TC de abdômen com "imagem em alvo" (seta) no quadrante inferior direito do abdômen.

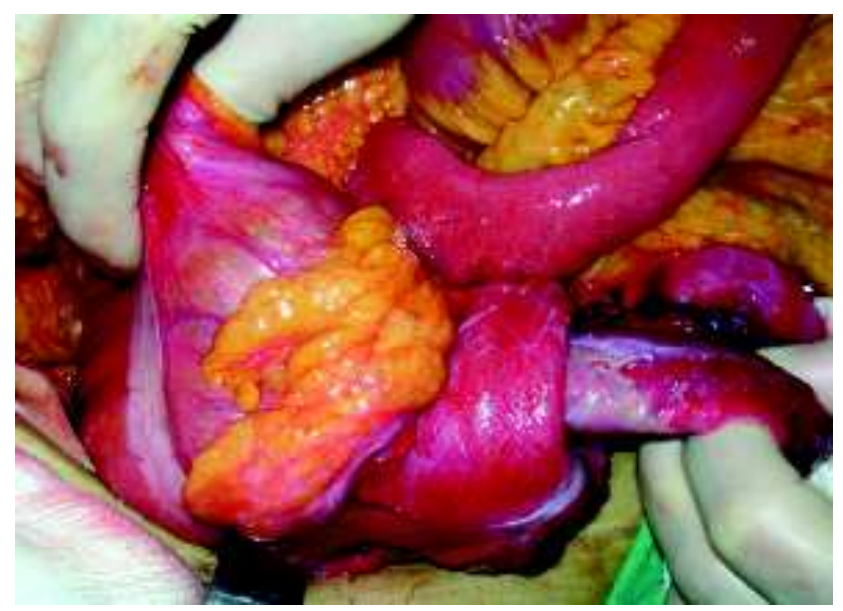

Figura 2 - Aspecto trans-operatório da intussuscepção íleo-cólica.
A análise anátomo-patológica convencional (hematoxilina-eosina) da peça operatória sugeriu tratarse de GIST ulcerado de padrão celular misto e baixa atividade mitótica, ressecado com margens cirúrgicas livres de neoplasia. Amostras da peça operatória foram, portanto, encaminhadas para confirmação diagnóstica por meio de avaliação imuno-histoquímica (IHQ), a qual acabou excluindo esta possibilidade pela negatividade dos marcadores CD117 (c-Kit), SMA, Desmina, CD34 e Proteína S100. Desta maneira, chegou-se ao diagnóstico final de pólipo fibróide inflamatório, após revisão dos exames. Por fim, a paciente foi orientada sobre os resultados encontrados e recebeu alta ambulatorial.

\section{DISCUSSÃO}

A intussuscepção intestinal foi inicialmente descrita na segunda metade do século XVII ${ }^{1}$, e apesar de relativamente comum entre as crianças, a invaginação de um segmento intestinal sobre outro raramente acomete os adultos, que representam atualmente $5 \%$ dos acometidos e para os quais a mesma constitui o fator etiológico de apenas $1-5 \%$ dos casos de obstrução intestinal ${ }^{1,2,3,4}$.

Enquanto na infância um fator causal habitualmente não pode ser identificado, entre os adultos a intussuscepção decorre de um fator etiológico bem definido em até $90 \%$ das vezes ${ }^{1,2,3,4,5}$. Um tumor maligno está envolvido em 20 a $50 \%$ dos casos em geral ${ }^{1}$, podendo atingir até $68 \%$ quando se considera somente o intestino grosso $^{3}$. Por outro lado, no intestino delgado, 1-40\% são decorrentes de neoplasias malignas, em sua maioria representadas por lesões metastáticas ${ }^{1}$. A idade média dos

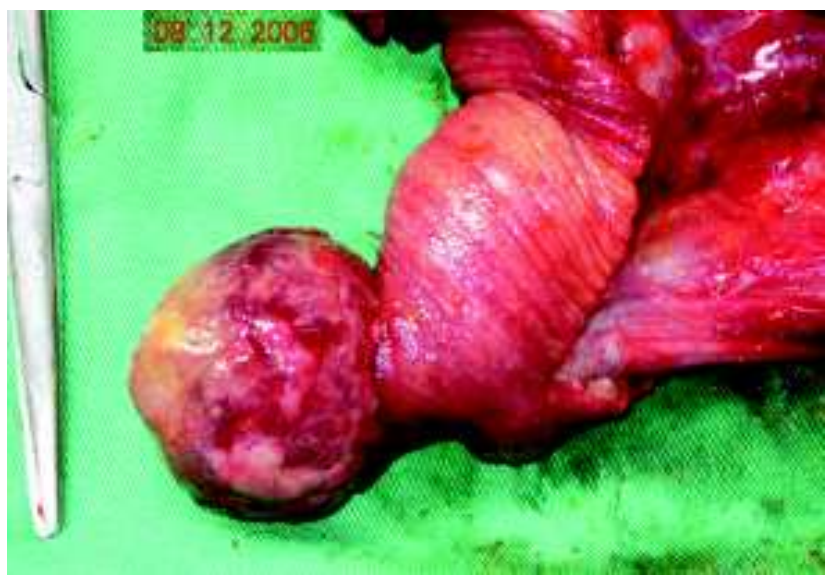

Figura 3 - Peça operatória aberta mostrando a "cabeça" da intussuscepção. 
acometidos varia de 40 a 57 anos, não havendo predominância clara sobre um ou outro sexo ${ }^{1,3}$.

De acordo com sua localização intestinal, as intussuscepções podem ser classificadas em entérica, íleo-cólica, ileocecal, colo-cólica, colo-retal e reto-retal. A localização entérica costuma ser a mais freqüente, ao passo que a topografia ileocecal representa de 9 a $35 \%$ dos casos ${ }^{1,2,3}$.

O quadro clínico é bastante variável, mas dor abdominal aflige praticamente todos os pacientes ${ }^{1,2,3,5}$. Outros sintomas encontrados são náuseas, vômitos, massa abdominal, constipação, diarréia, febre, meteorismo intestinal, enterorragia, parada da eliminação de gazes intestinais e/ou peritonite ${ }^{1,2}$. Sinais típicos de obstrução intestinal, contudo, estão presentes em apenas $50 \%$ dos pacientes ${ }^{1}$.

Os principais exames utilizados na investigação diagnóstica são radiografia simples, exames contrastados e tomografia computadorizada (TC) do abdômen, além de colonoscopia e ultra-sonografia (USG) ${ }^{1}$. No entanto, o diagnóstico pré-operatório de intussuscepção é realizado em somente um terço dos casos ${ }^{1,2,3}$. Os achados típicos de "imagem em alvo" ou em "salsicha", dependendo da projeção axial da intussuscepção durante o exame, são descritos na USG e TC e sugerem fortemente o diagnóstico de intussuscepção ${ }^{4}$. A colonoscopia e o enema baritado, ainda, podem ser terapêuticos em alguns poucos casos.

Neste relato, a USG não foi solicitada devido às limitações técnicas do método relacionadas à distensão gasosa promovida pela obstrução intestinal, preferindose a TC por disponibilizar imagens que podem ser avaliadas pelo radiologista e pela equipe cirúrgica.

O primeiro tratamento cirúrgico bem sucedido da intussuscepção somente foi citado em uma criança em $1871^{1}$, mas atualmente a abordagem operatória para este grupo etário restringe-se aos casos em que um enema terapêutico não foi bem sucedido ou na presença de sinais de peritonite e/ou perfuração intestinal na apresentação inicial. Para os adultos, todavia, seu tratamento requer abordagem individualizada ${ }^{1,2,3,5}$ e ge- ralmente envolve a ressecção dos segmentos intestinais acometidos ${ }^{1}$. Invaginações envolvendo os cólons devem ser preferivelmente submetidas à ressecção "en bloc" sem redução prévia, uma vez que a maior parte delas são decorrentes de neoplasias malignas 1,2,3,5. Para aquelas limitadas ao intestino delgado, e quando este for viável, pode-se lançar mão da redução antes da ressecção quando um diagnóstico benigno puder ser feito no pré-operatório ou uma ressecção mais alargada puder resultar em síndrome do intestino curto 1,2,5. Outras opções mais conservadoras devem ser desencorajadas ou limitadas a casos selecionados, mesmo levando em conta que um tratamento padrão ainda não tenha sido alcançado.

No referido caso, a redução foi taticamente empregada com o intuito de se poupar o ceco, que não apresentava comprometimento macroscópico pelo tumor. Empregou-se, ainda, apendicectomia com o intuito de se evitar confusão diagnóstica futura.

Por outro lado, os GISTs são neoplasias mesenquimais caracterizados por achados histológicos típicos e pela expressão do receptor Kit (CD117) por meio da IHQ, bem como de outros marcadores que podem estar positivos em percentuais variados dos casos. O emprego desta técnica, além de ser importante para seu diagnóstico diferencial, tem grande valor pela implicação de seu resultado sobre o tratamento, através da identificação dos casos respondedores ao STI571 (mesilato de imatinib), que representa a primeira droga a agir especificamente na alteração molecular responsável pela etiologia destes cânceres ${ }^{6}$.

A utilização do exame imuno-histoquímico da peça operatória foi fundamental para a realização do diagnóstico definitivo neste relato, servindo para afastar a possibilidade de GIST sugerida inicialmente pela análise anatomopatológica convencional.

Este artigo chama atenção pela raridade da entidade descrita, que pôde ser diagnosticada no pré-operatório pelo achado tomográfico característico na vigência de obstrução intestinal típica, assim como pelo adequado diagnóstico diferencial realizado através da IHQ.

\footnotetext{
ABSTRACT: Whereas intussusception is relatively common in children, it is clinically rare in adults and requires a high index of suspicion. Controversy remains regarding the optimal management of this problem in the adult patient, but its treatment usually requires resection of the involved intestinal segment because of the frequency of neoplasms and bowel ischemia. This article reports one uncommon case of intestinal obstruction due to ileocolic intussusception in an older woman treated by surgical approach.
}

Key words: Intussusception, invagination, adult, intestinal obstruction, GIST. 


\section{REFERÊNCIAS}

1. Zubaidi A, Al-Saif F, Silverman R. Adult Intussusception: A Retrospective Review. Dis Colon Rectum. 2006;49(10):154651.

2. Lebeau R, Koffi E, Diané B, Amani A, Kouassi JC. Invaginations intestinales aiguës de l'adulte : analyse d'une série de 20 cas. Ann Chir. 2006 Oct;131(8):447-50

3. Lucena MT, Apel A, Silva MJM. Intussuscepção no Adulto. Rev bras Coloproct, 2005;25(2):158-161.

4. Kim YH, Blake MA, Harisinghani MG, Archer-Arroyo K, Hahn PF, Pitman MB, Mueller PR. Adult intestinal intussusception: CT appearances and identification of a causative lead point. Radiographics. 2006;26(3):733-44.
5. Eisen LK, Cunningham JD, Aufses AH Jr. Intussusception in adults: institutional review. J Am Coll Surg. 1999;188(4):3905 .

6. Blay JY, Bonvalot S, Casali P, Choi H, Debiec-Richter M, Dei Tos AP, et al. Consensus meeting for the management of gastrointestinal stromal tumors. Report of the GIST Consensus Conference of 20-21 March 2004, under the auspices of ESMO. Ann Oncol. 2005;16(4):566-78.

\section{Endereço para correspondências:}

THALES PAULO BATISTA

Caixa Postal 3862 - 50110-970 - Recife-PE

E-mail: t.paulo@bol.com.br 